\title{
A phase II study of doxifluridine and docetaxel combination chemotherapy for advanced or recurrent gastric cancer
}

\author{
Takaki Yoshikawa ${ }^{1}$, Akira Tsuburaya ${ }^{1}$, Ken Shimada $^{2}$, Atsushi Sato ${ }^{3}$, Makoto Takahashi $^{4}$, \\ Wasaburo Koizumi ${ }^{5}$, Yasuo Yoshizawa ${ }^{6}$, Kazuhito Nabeshima ${ }^{7}$, Masayuki Kimura ${ }^{8}$, Kiyoshi Hataya ${ }^{9}$, \\ and OSAMU KOBAYASHI \\ ${ }^{1}$ Department of Gastrointestinal Surgery, Kanagawa Cancer Center, 1-1-2 Nakao, Asahi-ku, Yokohama 241-0815, Japan \\ ${ }^{2}$ Department of Internal Medicine, Showa University Northern Yokohama Hospital, Yokohama, Japan \\ ${ }^{3}$ Department of Medical Oncology, Showa University Hospital, Tokyo, Japan \\ ${ }^{4}$ Department of Surgery, Kamishirane Hospital, Yokohama, Japan \\ ${ }^{5}$ Department of Gastroenterology, Kitasato University East Hospital, Sagamihara, Japan \\ ${ }^{6}$ Department of Surgery, Showa University Fujigaoka Hospital, Yokohama, Japan \\ ${ }^{7}$ Department of Surgery, Tokai University School of Medicine, Isehara, Japan \\ ${ }^{8}$ Department of Surgery, St. Marianna University School of Medicine, Kawasaki, Japan \\ ${ }^{9}$ Department of Surgery, Yokohama Asahi Central and General Hospital, Yokohama, Japan
}

\begin{abstract}
Background. The aim of this study was to establish the efficacy and safety of doxifluridine and docetaxel for patients with advanced or recurrent gastric cancer.

Methods. The regimen consisted of oral administration of doxifluridine $533 \mathrm{mg} / \mathrm{m}^{2}$ per day on days 1-14 and an intravenous infusion of docetaxel $50 \mathrm{mg} / \mathrm{m}^{2}$ on day 8 . The primary endpoint was the overall response rate. The secondary endpoints were overall survival, progression-free survival, and toxicities.

Results. Between June 2004 and December 2006, a total of 40 eligible patients were enrolled in this study. Seven of them showed a partial response, with an overall response rate of $17.5 \%$. The response rate was $18.8 \%$ in 32 patients with refractory tumors. The median progression-free survival time and the median overall survival time were 2.6 months and $\mathbf{1 2 . 7}$ months, respectively, in all 40 patients; and 2.6 months and 14.0 months, respectively, in the 32 patients with refractory tumors. Grade 3/4 hematological toxicity included neutropenia in $\mathbf{5 2 . 5} \%$, leukocytopenia in $\mathbf{1 7 . 5} \%$, and febrile neutropenia in $7.5 \%$. Grade 3 or more nonhematological toxicities were infrequent.

Conclusion. The combination chemotherapy of doxifluridine and docetaxel was well tolerated and relatively effective when used as a second-line chemotherapy for advanced or recurrent gastric cancer.
\end{abstract}

Key words Doxifluridine $\cdot$ Docetaxel $\cdot$ Chemotherapy $\cdot$ Phase II - Gastric cancer

Offprint requests to: T. Yoshikawa

Received: August 6, 2009 / Accepted: October 15, 2009

\section{Introduction}

The prognosis of patients with metastatic gastric cancer is extremely poor. The median survival time of these patients is approximately 3 to 4 months with the best supportive care [1-3]. Several randomized phase III studies comparing best supportive care and combination chemotherapy have revealed that the overall survival was significantly prolonged in patients who received chemotherapy, suggesting that chemotherapy should be recommended for these patients [1-3]. New drugs, such as $\mathrm{S}-1$ ( $1 \mathrm{M}$ tegafur- $0.4 \mathrm{M}$ gimestat- $1 \mathrm{M}$ otastat potassium) $[4,5]$, paclitaxel $[6,7]$, docetaxel $[8,9]$ and irinotecan hydrochloride (CPT-11) [10], have been developed and several combination regimens have been tested in Japan.

Docetaxel, a taxane, is an antimicrotubule agent that enhances the polymerization of tubulin into stable microtubules and inhibits microtubule depolymerization [11]. It has shown promising activity in gastric cancer both as a single agent and in combination with other agents. TAX 325, a recent phase III study, demonstrated that overall survival with triple-agent chemotherapy using docetaxel, 5-fluorouracil (5-FU), and cisplatin was significantly superior to that of 5-FU and cisplatin [12]. However, this triplet chemotherapy had severe toxicity. Moreover, 5-FU and cisplatin need the patients to be hospitalized for administration. Oral 5-FU analogues and prodrugs are attractive alternative agents for combination with docetaxel.

Doxifluridine is an oral fluoropyrimidine that is metabolized to 5-FU by thymidine phosphorylase, which is mainly activated in the tumor tissue [13]. Doxifluridine is also known as an intermediate metabolite in 
the conversion of capecitabine to 5-FU [14]. Capecitabine has been widely used all over the world except in Japan, where it has not been approved for gastric cancer. Doxifluridine is less toxic than systemically administered 5-FU [14], as the conversion of doxifluridine into 5-FU takes place mainly in the tumor tissue [15]. The most prominent toxicity of doxifluridine is reportedly diarrhea [14]. Doxifluridine is active against gastric cancer both as a single agent and in combination with other drugs.

Thus, docetaxel and doxifluridine have different mechanisms of antitumor activity and they have different toxicity profiles. The fact that the dose-limiting toxicities of the two drugs did not overlap seemed to be an advantage when compared with combinations such as docetaxel and S-1. Moreover, taxanes have been shown to upregulate the enzyme activity of thymidine phosphorylase in a human colon cancer xenograft model, and thereby the tumor sensitivity to doxifluridine or capecitabine may be enhanced [16]. Several combinations of taxanes with these two oral fluoropyrimidines have been developed and tested in solid tumors, among which the present combination was investigated in patients with breast cancer and proved to be active and well tolerated [17]. These findings prompted the authors to conduct a phase I study of a combination of doxifluridine, administered for 14 consecutive days every 3 weeks, and docetaxel, given on day 8 , in gastric cancer patients [18]. The recommended dose was determined as docetaxel $50 \mathrm{mg} / \mathrm{m}^{2}$ and doxifluridine $533.3 \mathrm{mg} / \mathrm{m}^{2}$ per day [18].

Based on these reports, we initiated a phase II study to further evaluate the efficacy and toxicity profile of this regimen in patients with metastatic gastric cancer. As docetaxel is considered to be equally active regardless of previous chemotherapy, we allowed the registration of pretreated patients, provided that the previous chemotherapy of up to two regimens had not contained taxanes.

\section{Patients and methods}

\section{Selection of patients}

The eligibility criteria were: histologically or cytologically confirmed unresectable or recurrent gastric adenocarcinoma; at least one measurable lesion or a primary tumor; possible oral intake; less than two prior regimens which did not include a taxane, completed at least 2 weeks before entry; age range from 20 to 80 years; Eastern Cooperative Oncology Group (ECOG) performance status 0-2; an estimated survival of at least 2 months; sufficient organ function (white blood cell [WBC] count $\geq 3000 / \mathrm{mm}^{3}$ and $\leq 12000 / \mathrm{mm}^{3}$, neutrophil count $\geq 1500 / \mathrm{mm}^{3}$, platelet count $\geq 100000 / \mathrm{mm}^{3}$, GOT $\leq 100 \mathrm{U} / 1$ and GPT $\leq 100 \mathrm{U} / \mathrm{l}$, total bilirubin $<1.5 \mathrm{mg} / \mathrm{dl}$, creatinine $<1.5 \mathrm{mg} / \mathrm{dl}$, normal ECG), and the patient's written informed consent. The exclusion criteria were a past history of allergic reactions to the medications, a severe medical condition, a symptomatic infectious disease, peripheral neuropathy or edema of grade 2 or greater, interstitial pneumonitis or lung fibrosis, symptomatic pleural effusion or ascites, clinically apparent brain metastasis, synchronous neoplasms which required treatment, and women who were pregnant or lactating.

\section{Treatment schedule}

One cycle consisted of 3 weeks. Doxifluridine $533.3 \mathrm{mg} /$ $\mathrm{m}^{2}$ per day was given orally twice daily for 2 weeks followed by a drug-free interval of 1 week. Docetaxel $50 \mathrm{mg} / \mathrm{m}^{2}$ was administered as at least a 1 -h infusion on day 8 . Dexamethasone $8 \mathrm{mg}$ was infused $1 \mathrm{~h}$ before docetaxel administration to reduce the risk of hypersensitivity reaction. Granulocyte colony-stimulating factor was permitted if a patient developed grade 4 neutropenia or febrile neutropenia. Primary prophylaxis was not allowed. Treatment was continued until disease progression, unacceptable toxicity, patient refusal, or the physician's decision to stop treatment.

Toxicity was graded according to the National Cancer Institute common toxicity criteria version 2.0 . At the initiation of each course, if the patient had a WBC count of $3000 / \mathrm{mm}^{3}$ or lower, neutrophil count of $1500 / \mathrm{mm}^{3}$ or lower, platelet count of $100000 / \mathrm{mm}^{3}$ or lower, total bilirubin of $2.0 \mathrm{mg} / \mathrm{dl}$ or higher, creatinine of $1.5 \mathrm{mg} / \mathrm{dl}$ or higher, GOT and GPT of $100 \mathrm{U} / 1$ or higher, alkaline phosphatase of grade 1 or higher, or nonhematological toxicities of grade 3 or higher, the drug administration was postponed until recovery from these adverse events. If the adverse events persisted for an additional 2 weeks, then the chemotherapy was stopped. If the patient had a history of postponement of chemotherapy due to these adverse events, or had neutropenia of grade 4, febrile neutropenia, a platelet count of $100000 / \mathrm{mm}^{3}$ or lower, or nonhematological toxicities of grade 3 or higher other than diarrhea, nausea, vomiting, appetite loss, fatigue, or hypersensitivity, then the next doses of doxifluridine and docetaxel were reduced to $400 \mathrm{mg} / \mathrm{m}^{2}$ and $40 \mathrm{mg} / \mathrm{m}^{2}$, respectively. If the patient had diarrhea of grade 3 or higher, then the next dose of doxifluridine was reduced to $400 \mathrm{mg} / \mathrm{m}^{2}$.

\section{Statistical considerations}

The primary endpoint was the response rate. The clinical response was evaluated once every cycle by the response evaluation criteria in solid tumors (RECIST), 
with a central review by two extramural physicians. A primary analysis was conducted to assess whether the lower limit of the $95 \%$ confidence interval (CI) of the response rate was greater than $7 \%$. We assumed a response rate of $20 \%$ and a threshold setting of $7 \%$. With a statistical power of $80 \%$, a total of 39 patients were required. Considering the possible inclusion of ineligible patients, we planned to enroll 41 patients. The secondary endpoints were overall survival, progressionfree survival, and toxicities. The overall survival was defined as the time from the date of registration to death due to any cause. Progression-free survival was defined as the time from registration until tumor progression or any cause of death, and was finally determined by a meeting of investigators and the radiological review committee. Toxicities were evaluated once every week. Eight institutions constituting the Gastric Cancer Synergistic Effect Chemotherapy Group participated in the trial, which was approved by the institutional review boards of all institutions.

\section{Results}

Between June 2004 and December 2006, a total of 41 patients were enrolled in this study. One patient was judged as ineligible, because this patient did not fulfill the criteria for initiating the first course of chemotherapy, due to a decrease in the WBC count after the enrollment. The characteristics of the 40 eligible patients are summarized in Table 1. One patient was not assessable, but was included in the intention-to-treat analysis and kept in the denominator of the response rate. The details of prior chemotherapy are shown in Table 2 . Only 3 patients were chemotherapy-naïve, while the other 37 patients $(93 \%)$ had received prior chemotherapy. When "refractory tumors" were defined as: (1) progressive disease according to RECIST during therapeutic chemotherapy or (2) tumors that had recurred within 6 months after completing the perioperative chemotherapy, 32 patients had refractory tumors. Of these 32 patients, 31 had S1-refractory tumors.
The patients completed a median of 3 cycles of the treatment (range, 1-12). The response rate is shown in Table 3. Seven of the 40 patients showed a partial response, with an overall response rate of $17.5 \%(95 \%$ CI, $5.2 \%$ to $29.8 \%$ ). Fourteen patients showed stable disease. When the 3 chemotherapy-naïve patients were excluded, the response rate was $18.9 \%$ (95\% CI, 5.7\% to $32.2 \%$; Table 3 ). The response rate was $18.8 \%$ in the

Table 1. The patients' characteristics

\begin{tabular}{ll}
\hline Age, in years, median (range) & $64(41-77)$ \\
Sex (male/female) & $34 / 6$ \\
Performance status (0/1/2) & $27 / 11 / 2$ \\
Primary/recurrent & $20 / 20$ \\
Histology (differentiated/poorly differentiated) & $31 / 9$ \\
Prior chemotherapy & 3 \\
$\quad$ No & 35 \\
1 & 2 \\
2 & \\
Disease site & 16 \\
$\quad$ Primary tumor & 14 \\
$\quad$ Liver & 21 \\
$\quad$ Lymph nodes & 13 \\
$\quad$ Peritoneum & \\
\hline
\end{tabular}

Table 2. Details of prior chemotherapy

\begin{tabular}{lcc}
\hline & All & Refractory \\
\hline One prior regimen & 35 & 30 \\
Therapeutic chemotherapy & 12 & 11 \\
S1 & 12 & 12 \\
S1+CDDP & 1 & 1 \\
S1+CPT-11 & 2 & 1 \\
CPT-11+CDDP & & \\
Perioperative chemotherapy & 1 & 1 \\
Pre-/Postoperative chemotherapy & 1 & 1 \\
S1/S1 & 1 & 0 \\
S1+CDDP/S1 & 5 & 3 \\
S1+CDDP/none & 2 & 2 \\
$\quad$ None/S1 & 1 & 1 \\
Two prior regimens & 1 & 1 \\
Therapeutic chemotherapy & \\
CPT-11+CDDP/S1 & \\
Postoperative UFT/Therapeutic S1 & 1 & \\
\hline
\end{tabular}

S1, $1 \mathrm{M}$ tegafur-0.4 $\mathrm{M}$ gimestat-1 $\mathrm{M}$ otastat potassium; CDDP, cisplatin; CPT-11, irinotecan hydrochloride; UFT, tegafur

Table 3. Response

\begin{tabular}{|c|c|c|c|c|c|c|}
\hline & CR & PR & $\mathrm{IR} / \mathrm{SD}$ & $\mathrm{PD}$ & $\mathrm{NE}$ & Response rate $(95 \% \mathrm{CI})$ \\
\hline Total $(n=40)$ & 0 & 7 & 14 & 18 & 1 & $17.5 \%(5.2-29.8 \%)$ \\
\hline \multicolumn{7}{|l|}{ Prior chemotherapy } \\
\hline No $(n=3)$ & 0 & 0 & 1 & 2 & 0 & $0 \%$ \\
\hline Yes $(n=37)$ & 0 & 7 & 13 & 15 & 2 & $18.9 \%(5.7-32.2 \%)$ \\
\hline $1(n=35)$ & 0 & 6 & 12 & 15 & 2 & $17.1 \%(4.0-30.3 \%)$ \\
\hline $2(n=2)$ & 0 & 1 & 1 & 0 & 0 & $50 \%$ \\
\hline \multicolumn{7}{|l|}{ Refractory } \\
\hline All $(n=32)$ & 0 & 6 & 12 & 13 & 1 & $18.8 \%(4.5-33.1 \%)$ \\
\hline S1-refractory $(n=31)$ & 0 & 6 & 12 & 13 & 0 & $19.4 \%(4.6-34.1 \%)$ \\
\hline
\end{tabular}

$\overline{\mathrm{CR}}$, complete response; PR, partial response; $I R / S D$, incomplete response/stable disease; PD, progressive disease; NE, not evaluable; CI, confidence interval 


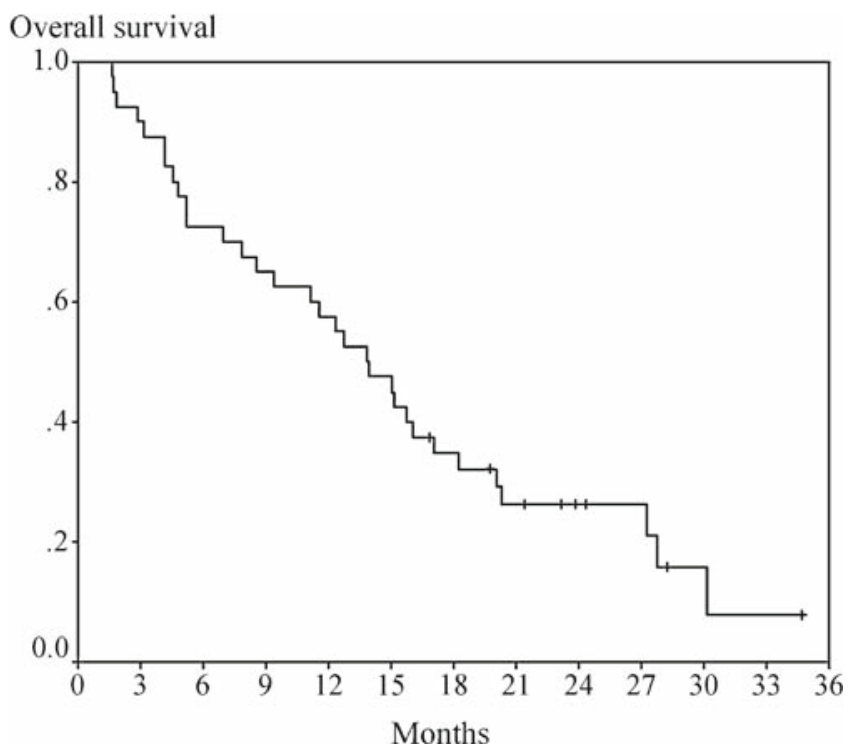

Fig. 1. Overall survival (intention-to-treat [ITT]; $n=40$ )

Progression-free survival

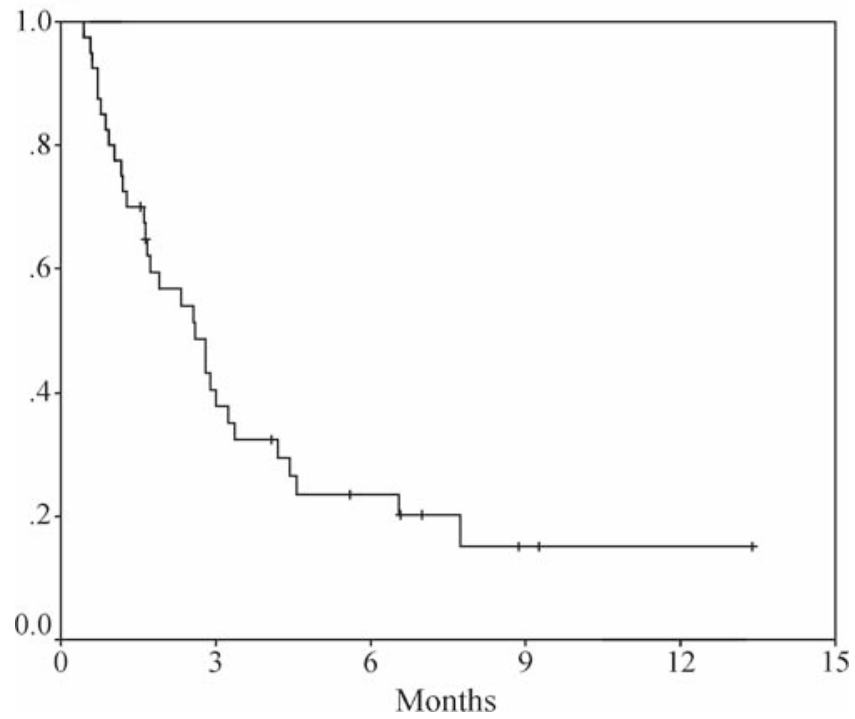

Fig. 2. Progression-free survival (ITT; $n=40)$

32 patients with refractory tumors and $19.4 \%$ in the 31 patients with S1-refractory tumors.

All eligible patients were followed up for more than 12 months after the enrollment. The median follow-up period was 23.2 months. At the time of analysis, 32 patients had already died. The median overall survival and the median progression-free survival in all 40 patients were 12.7 months and 2.6 months, respectively (Figs. 1 and 2), and 14.0 months and 2.6 months, respectively, in the 32 patients with refractory tumors (Figs. 3 and 4).
Overall survival

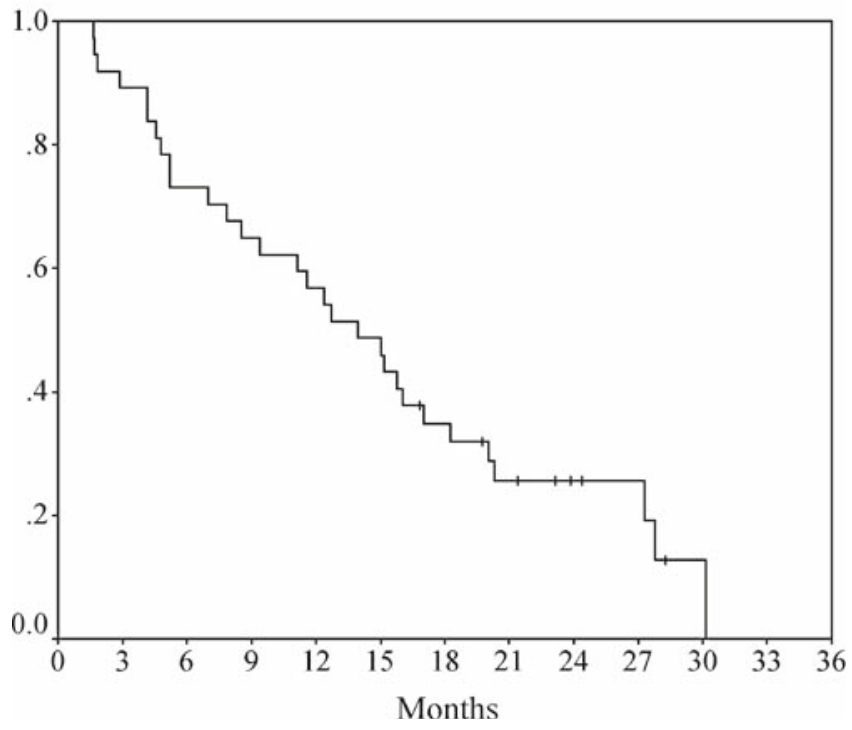

Fig. 3. Overall survival in 32 patients with refractory tumors not responding to previous chemotherapy

Progression-free survival

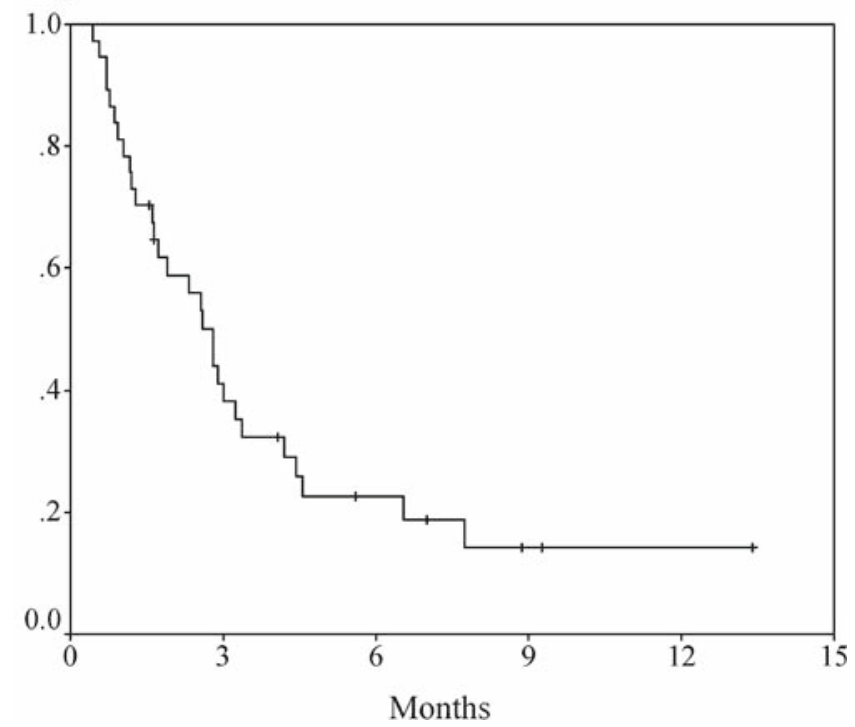

Fig. 4. Progression-free survival in 32 patients with refractory tumors not responding to previous chemotherapy

The toxicities are summarized in Table 4. The most common grade 3 or 4 hematological toxicity was neutropenia $(52.5 \%)$. Febrile neutropenia was observed in $7.5 \%$. On the other hand, grade 3 or more nonhematological toxicities were rare, including fever $(5 \%)$, anorexia (5\%), stomatitis $(2.5 \%)$, and edema $(2.5 \%)$. No treatment-related death was observed. 
Table 4. Toxicities

\begin{tabular}{|c|c|c|c|c|c|}
\hline & \multicolumn{4}{|c|}{ All grades } & \multirow{2}{*}{$\begin{array}{c}\text { Grade } 3 / 4 \\
(\%)\end{array}$} \\
\hline & 1 & 2 & 3 & 4 & \\
\hline Leukopenia & 5 & 17 & 5 & 2 & 17.5 \\
\hline Neutropenia & 3 & 5 & 8 & 13 & 52.5 \\
\hline Hemoglobin & 20 & 11 & 2 & 3 & 12.5 \\
\hline Platelets & 10 & 2 & 0 & 0 & 0 \\
\hline Febrile neutropenia & - & - & 3 & 0 & 7.5 \\
\hline Anorexia & 14 & 3 & 2 & 0 & 5.0 \\
\hline Nausea & 5 & 2 & 0 & 0 & 0 \\
\hline Vomiting & 5 & 0 & 0 & 0 & 0 \\
\hline Stomatitis & 5 & 2 & 1 & 0 & 2.5 \\
\hline Diarrhea & 4 & 1 & 0 & 0 & 0 \\
\hline Neuropathy-sensory & 6 & 1 & 0 & 0 & 0 \\
\hline Taste alteration & 2 & 0 & 0 & 0 & 0 \\
\hline Nail changes & 2 & 0 & 0 & 0 & 0 \\
\hline Pigmentation & 1 & 0 & 0 & 0 & 0 \\
\hline Fever & 3 & 1 & 2 & 0 & 5.0 \\
\hline Fatigue & 14 & 3 & 0 & 0 & 0 \\
\hline Edema: limb & 4 & 0 & 1 & 0 & 2.5 \\
\hline Allergic reaction & 0 & 0 & 0 & 0 & 0 \\
\hline Alopecia & 11 & 7 & - & - & - \\
\hline
\end{tabular}

\section{Discussion}

A combination of either capecitabine or doxifluridine with the taxanes that upregulate thymidine phosphorylase activity [16] is theoretically promising, and has been evaluated with various types of cancer. Among these two, only doxifluridine is available for the treatment of gastric cancer in Japan. As a combination of this drug with paclitaxel has already been explored [19], the authors chose to explore a combination with docetaxel. The response rate of this combination chemotherapy was lower than expected, at $17.5 \%$, and our statistical hypothesis in this phase II study was not met. One of the reasons could be that most patients were not chemonaive in the study population. While our study was accruing patients, two other important phase III trials to find the standard first-line chemotherapy for gastric cancer were taking place, and one of the candidate agents in both of the trials was S-1. This could partially explain why only three patients in the present study were chemotherapy-naïve. Anyhow, the activity of the present regimen in the first-line setting could not be evaluated. Among the 40 patients who were enrolled in this study, 35 had received one prior regimen and 32 had refractory tumors. Thus, the results observed in this study should be interpreted essentially as those of a phase II trial in the second-line setting, which generally results in lower response rates.

Since S1 plus cisplatin was established as the standard first-line chemotherapy in Japan, based on several phase III trials [20-22], attention had been focused clinically on the development of second-line chemotherapy. In the present study, the response rate was $18.8 \%$ in the 32 patients who received the trial regimen as secondor third-line chemotherapy. In particular, the response rate was $19.4 \%$ for the patients with S1-refractory tumors. Several investigators have reported on the efficacy of second-line chemotherapy for gastric cancer using various combinations of docetaxel with another anticancer agent. Response rates in these combinations ranged from $10.5 \%$ to $29 \%$ [23-28]. Thus, our result was equivalent to those in most of these studies.

The response rate is generally expected to be higher with combination therapy than with single-agent treatment. In fact, the response rates were reported to be $21.7 \%$ and $21.9 \%$ among pretreated patients in two independent phase II studies of docetaxel as a single agent $[8,9]$. The response rate of the present combination of docetaxel and doxifluridine was found not to be superior to the response rate of single-agent therapy, and this could be considered as a drawback. Surprisingly, however, the toxicity profile of the present combination was milder than that of the monotherapy. The predominant grade 3 or more adverse events affected neutrophils in $52.5 \%$, leucocytes in $17.5 \%$, and hemoglobin in $12.5 \%$. Febrile neutropenia was observed in $7.5 \%$. The major known toxicities of docetaxel are bone marrow suppression, especially leukocytopenia, neutropenia, and febrile neutropenia $[8,9]$. These were also dose-limiting toxicities in most regimens containing docetaxel. All hematological toxicities in the present trial were not so frequent and manageable. On the other hand, compared with results in the present trial, bone marrow suppression was reportedly more severe and more frequently observed with other regimens containing docetaxel [23-27]. In the present regimen, docetaxel at a dose of $50 \mathrm{mg} / \mathrm{m}^{2}$ was given every 3 weeks, but in other regimens it was given at a dose of $60 \mathrm{mg} / \mathrm{m}^{2}$ to $75 \mathrm{mg} / \mathrm{m}^{2}$ every 3 weeks [23-25, 27, 28]. Thus, the lower dose intensity in the present trial may have contributed to the severity and the incidence of myelosuppression observed in this study. In addition, nonhematological toxicities were rare in the present study. Grade 3 or more gastrointestinal toxicities were seen in fewer than $5 \%$. Neither hand-foot syndrome nor grade 3 or more diarrhea occurred. In a phase II study using doxifluridine, hand-foot syndrome was not observed, but diarrhea occurred in $26.3 \%$ [15]. Rosati et al. [27] reported that hand-foot syndrome of grade 3 or more was observed in $7 \%$ and grade 3 diarrhea was observed in $11 \%$ with docetaxel and capecitabine as second-line chemotherapy for metastatic gastric cancer. Again, the relatively low dose intensity of doxifluridine in our study may have contributed to the severity and the incidence of diarrhea observed in this study.

In contrast to the response rate, the median overall survival time in the present study was longer than 
expected from the study population: 12.7 months in all 40 patients and 14.0 months in the 32 patients with refractory tumors. The median overall survival time in the present study ( $>12$ months) was similar to that seen with first-line chemotherapy in several phase III studies. In the phase III trial of S-1 plus cisplatin versus S-1 alone for the first-line treatment of advanced gastric cancer (SPIRITS), the median overall survival time was 13.0 months with S1 and cisplatin and 12.0 months with $\mathrm{S} 1$ alone [21]. In the Japanese Clinical Oncology Group (JCOG) 9912 trial, the median overall survival time was 10.8 months with 5-FU, 12.3 months with CPT-11 and cisplatin, and 11.4 months with S1 [20]. In several previous reports of second-line chemotherapy, the median overall survival time ranged from 4 to 9 months [25-28]. In contrast to the overall survival time in the present study, the median progression-free survival was unimpressive, at 2.6 months, meaning that the patients generally lived long after disease progression. This may have been due to the successful introduction of effective third-line chemotherapy, but detailed information regarding this issue was not looked at in this trial.

To conclude, although the efficacy of the present doxifluridine/docetaxel combination in the first-line setting was not evaluated, this combination could be feasible as second-line chemotherapy. Although the dose intensities of docetaxel and doxifluridine were relatively low, the response rate and progression-free survival were moderate and the overall survival was excellent. The mild toxicity profile of the present regimen may have increased treatment compliance, and this may have made it easier for the patients to accept further lines of therapy when the disease failed to respond to this combination; these factors may have been causes of the prolonged overall survival.

\section{References}

1. Pyrhonen S, Kuitunen T, Nyandoto P, Kouri M. Randomised comparison of fluorouracil, epidoxorubicin and methotrexate (FEMTX) plus supportive care with supportive care alone in patients with non-resectable gastric cancer. Br J Cancer 1995;71: 587-91.

2. Murad AM, Santiago FF, Petroianu A, Rocha PR, Rodrigues MA, Rausch M. Modified therapy with 5-fluorouracil, doxorubicin, and methotrexate in advanced gastric cancer. Cancer 1993;72: $37-41$.

3. Glimelius B, Hoffman K, Haglund U Nyren O, Sjoden PO. Initial or delayed chemotherapy with best supportive care in advanced gastric cancer. Ann Oncol 1994;5:189-90.

4. Koizumi W, Kurihara M, Nakano S, Hasegawa K. Phase II study of S-1, a novel oral derivative of 5-fluorouracil, in advanced gastric cancer. Oncology 2000;58:191-7.

5. Sakata Y, Ohtsu A, Horikoshi N, Sugimachi K, Mitachi Y, Taguchi T. Late phase II study of novel oral fluoropyrimidine anticancer drug S-1 (1 M tegafur- $0.4 \mathrm{M}$ gimestat- $1 \mathrm{M}$ otastat potassium) in advanced gastric cancer patients. Eur J Cancer 1998;34:1715-20.
6. Yamada Y, Shirao K, Ohtsu A, Boku N, Hyodo I, Saitoh H, et al. Phase II trial of paclitaxel by 3-h infusion for advanced gastric cancer with short premedication for prophylaxis against paclitaxel-associated hypersensitivity. Ann Oncol 2001;12: 1133-7.

7. Yamaguchi K, Tada M, Horikoshi N, Otani T, Takiuchi H, Saitoh S, et al. Phase II study of paclitaxel 3-h infusion in patients with advanced gastric cancer. Gastric Cancer 2002;5: $55-7$.

8. Taguchi T, Sakata Y, Kanamaru R, Kurihara M, Suminaga M, Ota J, et al. Late phase II clinical study of RP56976 (docetaxel) in patients with advanced/recurrent gastric cancer. a Japanese Cooperative Study Group trial (group A). Jpn J Cancer Chemother 1998;25:1915-24.

9. Mai M, Sakata Y, Kanamaru R, Kurihara M, Suminaga M, Ota J, et al. A late phase II clinical study of RP56976 (docetaxel) in patients with advanced or recurrent gastric cancer. A cooperative study group trial (group B). Jpn J Cancer Chemother 1999;26: 487-96.

10. Futatsuki K, Wakui A, Nakao I, Sakata Y, Kambe M, Shimada Y, et al. Late phase II study of irinotecan hydrochloride (CPT-11) in advanced gastric cancer. Jpn J Cancer Chemother 1994;21: 1033-8.

11. Wang LG, Liu XM, Kreis W, Budman DR. The effect of antimicrotubule agents on signal transduction pathways of apoptosis: a review. Cancer Chemother Pharmacol 1999;44: 355-61.

12. Van Cutsem E, Moiseyenko VM, Tjulandin S, Majlis A, Constenla M, Boni C, et al. Phase III study of docetaxel and cisplatin plus fluorouracil compared with cisplatin and fluorouracil as firstline therapy for advanced gastric cancer: a report of the V325 study. J Clin Oncol 2006;24:4991-7.

13. Ishitsuka H, Miwa M, Takemoto K, Fukuoka K, Itoga A, Maruyama $\mathrm{H}$. Role of uridine phosphorylase for antitumor activity of 5'-deoxy-5-fluorouridine. Gann 1980;71:112-23.

14. Niitani H, Kimura K, Saito T, Nakao I, Abe O, Urushizaki I, et al. Phase II study of $5^{\prime}$-deoxy-5-fluorouridine (5'-DFUR) on patients with malignant cancer. Multi-institutional cooperative study. Jpn J Cancer Chemother 1985;12:2044-51.

15. Miwa M, Ura M, Nishida M, Sawada N, Ishikawa T, Mori K, et al. Design of a novel oral fluoropyrimidine carbamate, capecitabine, which generates 5-fluorouracil selectively in tumours by enzymes concentrated in human liver and cancer tissue. Eur J Cancer 1998;34:1274-81.

16. Sawada N, Ishikawa T, Fukase Y, Nishida M, Yoshikubo T, Ishitsuka $\mathrm{H}$. Induction of thymidine phosphorylase activity and enhancement of capecitabine efficacy by taxol/taxotere in human cancer xenografts. Clin Cancer Res 1996;4:1013-9.

17. Nishimura R, Tominaga T, Mitsuyama S, Aoyama H, Asaga T, Ohno S, et al. Combination chemotherapy with docetaxel and doxifluridine showed a beneficial outcome in advanced or recurrent breast cancer patients with longer disease-free interval. Anticancer Res 2004;24:2085-91.

18. Sato A, Shimada K, Matsukawa M, Taguchi S. A phase I study of combination chemotherapy of docetaxel and doxifluridine for unresectable or recurrent gastric cancer. Presented at the 76th annual meeting of the Japanese Gastric Cancer Association, 2004. p. 1646.

19. Takiuchi H, Goto M, Imamura H, Furukawa H, Imano M, Imamoto $\mathrm{H}$, et al. Multi-center phase II study for combination therapy with paclitaxel/doxifluridine to treat advanced/recurrent gastric cancer showing resistance to S-1 (OGSG 0302). Jpn J Clin Oncol 2008;38:176-81.

20. Boku N, Yamamoto S, Shirao K, Doi T, Sawaki A, Koizumi W, et al. Randomized phase III study of 5-fluorouracil (5-FU) alone versus combination of irinotecan and cisplatin $(\mathrm{CP})$ versus S-1 alone in advanced gastric cancer (JCOG 9912). Presented at the 43rd Annual Meeting of American Society of Clinical Oncology, Chicago, IL, June 1-5, 2007 (abstract LBA4513). 
21. Koizumi W, Narahara H, Hara T, Takagane A, Akiya T, Takagi $\mathrm{M}$, et al. S-1 plus cisplatin versus S-1 alone for first-line treatment of advanced gastric cancer (SPIRITS trial): a phase III trial. Lancet Oncol 2008;9:215-21.

22. Imamura $H$, Ishii $H$, Tsuburaya $A$, Hatake $K$, Imamoto $H$, Esaki $\mathrm{T}$, et al. Randomized phase III study of irinotecan plus S-1 (IRIS) versus S-1 alone as first-line treatment for advanced gastric cancer (GC0301/TOP-002). Presented at the 2008 Gastrointestinal Cancers Symposium, Orlando, FL, January 25-27, 2008 (abstract $5)$.

23. Kunisaki C, Imada T, Yamada R, Hatori S, Ono H, Otsuka Y, et al. Phase II study of docetaxel plus cisplatin as a second-line combined therapy in patients with advanced gastric carcinoma. Anticancer Res 2005;25:2973-8.

24. Park SH, Kang WK, Lee HR, Park J, Lee KE, Lee SH, et al. Docetaxel plus cisplatin as second-line therapy in metastatic or recurrent advanced gastric cancer progressing on 5-fluorouracilbased regimen. Am J Clin Oncol 2004;27:477-80.
25. Sym SJ, Chang HM, Kang HJ, Lee SS, Ryu MH, Lee JL, et al. A phase II study of irinotecan and docetaxel combination chemotherapy for patients with previously treated metastatic or recurrent advanced gastric cancer. Cancer Chemother Pharmacol 2008; 63:1-8.

26. Nguyen S, Rebischung C, Van Onqueval J, Flesch M, Bennamoun $\mathrm{M}$, André T, et al. Epirubicin-docetaxel in advanced gastric cancer: two phase II studies as second and first line treatment. Bull Cancer 2006;93:E1-6.

27. Rosati G, Bilancia D, Germano D, Dinota A, Romano R, Reggiardo G, et al. Reduced dose intensity of docetaxel plus capecitabine as second-line palliative chemotherapy in patients with metastatic gastric cancer: a phase II study. Ann Oncol 2007;18:128-32.

28. Barone C, Basso M, Schinzari G, Pozzo C, Trigila N, D'Argento $\mathrm{E}$, et al. Docetaxel and oxaliplatin combination in second-line treatment of patients with advanced gastric cancer. Gastric Cancer 2007;10:104-11. 